\title{
DESEMPENHO DE BOVINOS DE CORTE EM CONFINAMENTO ALIMENTADOS COM DIFERENTES FORRAGENS E ALOJADOS EM BAIAS INDIVIDUAIS OU COLETIVAS
}

(Performance of beef cattle in a feedlot fed different forages and housed in individual or collective pens)

Sergio Antonio Schwartz Custodio ${ }^{1}$, Diego Azevedo Leite da Silva², Rodrigo de Oliveira Goulart², Kaique Moreira Dias ${ }^{1}$, Tiago do Prado Paim², Eduardo Rodrigues de Carvalho

${ }^{1}$ Instituto Federal Goiano - Campus Rio Verde, ${ }^{2}$ Instituto Federal Goiano - Campus Iporá.

"Correspondência: eduardo.carvalho@ifgoiano.edu.br

RESUMO: As forragens desempenham um papel essencial no desempenho de bovinos de corte em confinamento. Vinte e quatro machos não castrados F1 Red Norte $\times$ Nelore com peso vivo médio (PV) inicial de 439,8 $\pm 59,6 \mathrm{~kg}$ e 21,7 $\pm 2,7$ meses de idade foram distribuídos em três grupos experimentas e alojados em baias individuais (doze animais) ou coletivas (doze animais em três baias) no Setor de Bovinocultura da Fazenda-Escola do IF Goiano (Câmpus Iporá). O experimento teve duração de 84 dias (14 dias para adaptação e 70 dias para coleta de dados). Alimentaram-se os animais uma vez ao dia com dietas à base de cana-de-açúcar in natura (Ci), silagem de cana (SC) ou silagem de milho (SM) como fontes de forragem, procurando-se obter 10 a $15 \%$ de sobras. Avaliou-se o consumo de matéria seca (CMS) diariamente pela diferença entre a quantidade oferecida menos a recusada, e registrou-se o PV dos animais a cada 14 dias após jejum de sólidos de doze horas. Não houve efeito $(P>0,05)$ da fonte de forragem sobre 0 CMS nos animais alojados nas baias individuais, assim como não houve resposta $(P>0,05)$ da fonte de forragem sobre o PV. Houve tendência $(P=0,09)$ de aumento do PV nos animais alojados em baias individuais $(561,4 \pm 21,2 \mathrm{~kg}) \mathrm{em}$ relação às baias coletivas (509 $\pm 21,2 \mathrm{~kg}$ ). As fontes de forragem não alteraram $(P>0,05)$ as características da carcaça. Os animais alojados nas baias individuais aumentaram $(\mathrm{P}<0,05)$ o peso do trato gastrintestinal vazio $(11,9 \mathrm{~kg})$, comparados aos animais alojados nas baias coletivas $(10,2 \mathrm{~kg})$. Houve tendência $(0,05 \leq P \leq 0,10)$ de aumento do PV pré-abate, peso do trato gastrintestinal cheio e peso do fígado nos animais alojados em baias individuais, em comparação às baias coletivas A Ci, SC e SM podem ser recomendadas na alimentação de bovinos de corte em confinamento.

Palavras-chave: cana-de-açúcar; consumo; peso vivo; Red Norte; silagem de milho

ABSTRACT: forages play a key role on the performance of beef cattle in feedlot systems. Twenty-four non-castrated F1 Red Norte $\times$ Nelore males with an average initial body weight (BW) of $439.8 \pm 59.6 \mathrm{~kg}$ and $21.7 \pm 2.7$ months of age were distributed in three experimental groups, and housed either in individual or collective pens (twelve animals in individual pens and twelve in three collective pens) at the Dairy and Beef Research and Education Center of the School-Farm of IF Goiano (Iporá Campus). The experiment lasted 84 days ( 14 days for adaptation and 70 days for data collection). Animals were fed once daily with diets containing sugar cane in natura (Ci), sugar cane silage (SC) or corn silage (CS) as sources of forage in amounts that ensured 10 to $15 \%$ of orts. Feed refusals were measured daily and dry matter intake (DMI) was determined by difference, BW was recorded every two weeks after a twelve-hour fasting period. There was no effect $(P>0.05)$ of source of forage on DMI in animals housed in individual pens, as well as there was no

Recebido em 03/02/2016

Aprovado em 22/03/2018 
response $(P>0.05)$ of source of forage on growth performance. There was a tendency $(P=$ $0.09)$ of BW increase in animals housed in individual pens $(561.4 \pm 21.2 \mathrm{~kg})$ compared with collective pen-housing $(509 \pm 21.2 \mathrm{~kg})$. Sources of forage did not alter $(P>0.05)$ carcass traits. Animals housed in individual pens increased $(\mathrm{P}<0.05)$ empty gastrointestinal tract weight $(11.9 \mathrm{~kg})$ compared with animals housed in collective pens $(10.2 \mathrm{~kg})$. There was a tendency $(0.05 \leq P \leq 0.10)$ of increase in pre-slaughter BW, full gastrointestinal tract weight and liver weight in animals housed in individual pens in comparison with collective pens. $\mathrm{Ci}, \mathrm{SC}$ and CS can be recommended for beef cattle feeding in feedlot systems.

Key Words: body weight; corn silage; intake; Red Norte; sugar cane

\section{INTRODUÇÃO}

A sazonalidade na produção de forragem e a falta de um planejamento nutricional estratégico ainda são as principais limitações para o crescimento da produtividade da pecuária de corte e da qualidade da carne bovina, na medida em que estes fatores determinam elevada idade de abate e inadequado acabamento de carcaça, resultando em uma baixa produtividade por unidade de área explorada (Anualpec, 2015). Com rentabilidade e taxa de desfrute muito baixas, os investimentos em pesquisa para 0 desenvolvimento de novas tecnologias visando o aumento da produtividade demonstram ser o melhor caminho para sanar as deficiências produtivas da pecuária de corte no Brasil.

O confinamento de bovinos de corte é uma estratégia que tem crescido na cadeia produtiva da carne bovina, devido a maiores taxas de ganho de peso diário, incrementos na produtividade e qualidade da carne (Menezes et al., 2010). Além disso, o confinamento possibilita que as variações das características da carne associadas ao grupo genético sejam minimizadas em função da redução na idade do abate e melhor acabamento da carcaça (Pacheco et al., 2005; Hadlich et al., 2006).

\section{A forragem possui importante} papel na formulação de rações para bovinos de corte em confinamento, uma vez que o custo com alimentação contribui com cerca de $70 \%$ do custo da terminação, e exerce influência sobre o desempenho animal (Brondani et al., 2004; Campos et al., 2010). Decréscimos no consumo de matéria seca (CMS) de forragens ocorrem em função da elevada concentração de fibra em detergente neutro (FDN), baixa palatabilidade, redução da taxa de passagem pelo rúmen e desbalanceamento no suprimento de aminoácidos e energia aos tecidos do animal (Mertens, 1987; Huhtanen et al., 2002).

No Brasil existem várias opções de forragens para utilização em confinamentos, dentre elas a silagem de milho e a cana-de-açúcar. Apesar da silagem de milho conter um valor nutricional mais elevado comparado à cana-de-açúcar (Velho et al., 2007; Zopollatto et al., 2009), a segunda tem sido utilizada na forma in natura (cortada e triturada diariamente) devido às suas características desejáveis, tais como alto rendimento de matéria seca (MS) e energia por unidade de área (Freitas et al., 2006), baixo risco na sua utilização como forragem, baixo custo por unidade de MS produzida e conservação do valor nutricional por um período prolongado após a sua maturação (Azevêdo et al., 2003; Costa et al., 2005). No entanto, em confinamentos com elevado número de animais, o corte e trituração diários da cana-de-açúcar podem se tornar um empecilho, pois os pecuaristas alegam dificuldades de logística operacional para realização destas atividades, fazendo com que a ensilagem da canade-açúcar seja uma opção interessante para conservação desta forragem por 
utilizar com mais eficiência a mão-deobra e maquinário da propriedade.

Objetivou-se neste trabalho determinar o efeito da alimentação da cana-deaçúcar in natura (Ci), silagem de cana (SC) ou silagem de milho (SM) sobre o desempenho de 24 bovinos machos inteiros F1 Red Norte $\times$ Nelore em confinamento, alojados em baias individuais ou coletivas. Testou-se a hipótese de que fontes de forragem $(\mathrm{Ci}$, SC ou SM) incluídas em diferentes proporções na $M S$ da ração não exercem influência sobre o desempenho animal, desde que os níveis nutricionais da dieta sejam semelhantes

\section{MATERIAL E MÉTODOS}

Conduziu-se o experimento no Setor de Bovinocultura da FazendaEscola do IF Goiano (Câmpus Iporá), entre 30 de junho a 15 de setembro de 2014 com duração de 84 dias, sendo 14 dias de adaptação dos animais às dietas experimentais e instalações, e 70 dias para coleta dos dados. Fez-se uso de 24 bovinos machos não castrados $\mathrm{F} 1$ Red Norte $\times$ Nelore com PV médio inicial de 439,8 $\pm 26,2 \mathrm{~kg}$ e idade média de 21,7 $\pm 2,7$ meses.

No dia 30 de junho de 2014 os animais receberam endectocida à base de Fenbendazole a $10 \%$ por via oral (5 $\mathrm{mg}$ de Fenbendazole/kg de PV) para prevenção de nematódeos gastrintestinais (incluindo as Taenia spp) e ectoparasiticida à base de $5 \%$ de Cipermetrina, 2,5\% de Clorpirifós e 1\% de Butóxido de Piperonila ao longo da espinha dorsal (10 mL/100 kg PV) para o controle de bernes (Dermatobia hominis), carrapatos (Rhipicephalus (Boophilus) microplus) e mosca dos chifres (Haematobia irritans). Após estas aplicações, os animais foram classificados quanto ao PV, distribuídos em três grupos experimentais conforme a fonte de forragem ( $\mathrm{Ci}, \mathrm{SC}$ ou $\mathrm{SM}$ ) e alojados em baias individuais (doze animais) ou em três baias coletivas (quatro animais/baia). As baias individuais mediam dois metros de largura por cinco metros de comprimento (10 $\mathrm{m}^{2} /$ animal) com fornecimento de sombra por telhas de zinco, enquanto que as baias coletivas mediam cinco metros de largura por dez metros de comprimento (12,5 $\mathrm{m}^{2} /$ animal) sem disponibilidade de sombra. A capacidade volumétrica dos comedouros nas baias individuais e coletivas era de 0,35 e 1,05 $\mathrm{m}^{3}$, respectivamente. O comprimento dos comedouros em cada baia coletiva era de $3,8 \mathrm{~m}$, disponibilizando 0,95 $\mathrm{m} /$ animal.

Os animais foram alimentados ad libitum uma vez ao dia entre 05:00 e 07:00 horas, em quantidades ajustadas diariamente para obter entre 10 a $15 \%$ de sobras, a fim de garantir o máximo consumo voluntário de MS. As três rações experimentais foram constituídas por $\mathrm{Ci}$, SC ou SM como fontes de forragem, além de milho desintegrado com palha e sabugo (MDPS), milho grão triturado, farelo de soja, ureia e núcleo mineral/vitamínico (Tabela 1).

Tabela 1- Ingredientes e composição nutricional das dietas experimentais 1 .

\begin{tabular}{|c|c|c|c|}
\hline Cana-de-açúcar in natura (Ci) & 22,0 & - & - \\
\hline Silagem de cana (SC) & - & 22,0 & - \\
\hline Silagem de milho (SM) & - & - & 32,0 \\
\hline MDPS $^{2}$ & 24,0 & 24,0 & 26,0 \\
\hline Milho triturado & 40,5 & 40,5 & 29,5 \\
\hline Farelo de soja & 10,0 & 10,0 & 9,0 \\
\hline Ureia protegida ${ }^{3}$ & 1,0 & 1,0 & 1,0 \\
\hline Núcleo vitamínico mineral ${ }^{4}$ & 2,5 & 2,5 & 2,5 \\
\hline \multicolumn{4}{|l|}{ Composição nutricional } \\
\hline MS, $\%$ & $67,60 \pm 3,28$ & $63,88 \pm 1,71$ & $57,20 \pm 1,97$ \\
\hline $\mathrm{PB}^{5}, \%$ da MS & $13,46 \pm 1,06$ & $14,75 \pm 0,87$ & $13,86 \pm 0,33$ \\
\hline $\mathrm{FDN}^{6}, \%$ da MS & $38,71 \pm 2,43$ & $38,77 \pm 2,88$ & $39,98 \pm 2,32$ \\
\hline $\mathrm{FDA}^{7}, \%$ da MS & $12,33 \pm 1,19$ & $12,29 \pm 1,44$ & $12,64 \pm 1,79$ \\
\hline Celulose $^{8}, \%$ da MS & $2,93 \pm 0,44$ & $1,66 \pm 0,25$ & $2,10 \pm 0,51$ \\
\hline Hemicelulose $^{9}, \%$ da MS & $26,38 \pm 1,65$ & $26,49 \pm 1,94$ & $27,35 \pm 1,79$ \\
\hline Lignina, \% da MS & $9,40 \pm 0,86$ & $10,63 \pm 1,27$ & $10,47 \pm 2,12$ \\
\hline Cinzas, $\%$ da MS & $4,94 \pm 0,65$ & $5,15 \pm 0,66$ & $6,11 \pm 0,55$ \\
\hline \multicolumn{4}{|c|}{${ }^{1}$ Médias $(n=5)$ e desvio padrão das análises nutricionais das dietas experimentais } \\
\hline \multirow{3}{*}{\multicolumn{4}{|c|}{$\begin{array}{l}{ }^{2} \text { milho desintegrado com palha e sabugo; }{ }^{3} 256,25 \% \text { equivalente proteína; }{ }^{4} 18 \% \mathrm{Ca} \text {, } \\
20 \mathrm{~g} / \mathrm{k} \mathrm{P}, 17 \mathrm{~g} / \mathrm{kg} \mathrm{Mg}, 26,7 \mathrm{~g} / \mathrm{kg} \mathrm{S}, 66,7 \mathrm{~g} / \mathrm{kg} \mathrm{na}, 25,2 \mathrm{mg} / \mathrm{kg} \mathrm{Co}, 416 \mathrm{mg} / \mathrm{kg} \mathrm{Cu}, 490 \\
\mathrm{mg} / \mathrm{kg} \mathrm{Fe}, 25,2 \mathrm{mg} / \mathrm{kg} \mathrm{I}, 832 \mathrm{mg} / \mathrm{kg} \mathrm{Mn}, 7 \mathrm{mg} / \mathrm{kg} \mathrm{Se}, 2.000 \mathrm{mg} / \mathrm{kg} \mathrm{Zn}, 833,5 \mathrm{mg} / \mathrm{kg}\end{array}$}} \\
\hline & & & \\
\hline & & & \\
\hline \multicolumn{4}{|c|}{ Monenzina, $83.200 \mathrm{UI} / \mathrm{kg}$ vitamina A, $10.400 \mathrm{UI} / \mathrm{kg}$ vitamina $\mathrm{D}, 240 \mathrm{UI} / \mathrm{kg}$ vitamina $\mathrm{E}}$, \\
\hline \multicolumn{4}{|c|}{${ }^{5}$ proteina bruta; ${ }^{6}$ fibra em detergente neutro; ${ }^{7}$ fibra em detergente neutro; ${ }^{8}$ celulose $=$} \\
\hline \multicolumn{4}{|c|}{ FDA - lignina; 9hemicelulose = FDN - FDA } \\
\hline
\end{tabular}

Adicionou-se inoculante bacteriano (2 $\mathrm{g}$ de produto comercial/ton. de matéria natural) à base de Lactobacillus 
plantarum (cepas CH6072 e L286) durante a ensilagem da cana-de-açúcar para redução na produção de etanol durante 0 processo fermentativo (Zopollatto et al., 2009).

As três dietas experimentais foram formuladas para serem isonitrogenadas e isofibrosas, e balanceadas para atender as exigências nutricionais diárias de bovinos de corte em confinamento com ganho de peso esperado de 1,8 kg/dia (NRC, 2000). Todos os protocolos experimentais foram aprovados pela Comissão de Ética no Uso de Animais (CEUA) do IF Goiano (parecer oㅜ 1/2014).

Amostras de $\mathrm{Ci}$, SC e SM foram coletadas semanalmente e levadas a uma estufa de ventilação forçada a $65^{\circ} \mathrm{C}$ durante 72 horas para determinação do teor de MS (AOAC, 2000), a fim de se manter constante o teor de nutrientes das dietas durante todo o período experimental. Posteriormente, as amostras de forragens foram moídas em moinho tipo Wiley dotado com peneira de $1 \mathrm{~mm}$ (Wiley Mill; Arthur H. Thomas, Philadelphia, PA), e analisadas para determinação de proteína bruta $(\mathrm{PB})$, cinzas (AOAC, 2000) e FDN (Goering e Van Soest, 1970). Os resíduos de FDN foram sequencialmente analisados quanto ao teor de fibra em detergente ácido (FDA) e lignina (Goering e Van Soest, 1970). Determinou-se a concentração de celulose pela diferença entre FDA - lignina, ao passo que a concentração de hemicelulose foi calculada pela diferença entre FDN FDA (Tabela 2).

Amostras do oferecido das dietas experimentais foram coletadas a cada 14 dias e congeladas a $-4^{\circ} \mathrm{C}$. Após $\mathrm{O}$ término do experimento, as amostras foram descongeladas em temperatura ambiente, reunidas para formar uma amostra composta de cada tratamento/14 dias, e levadas a uma estufa de ventilação forçada a $65^{\circ} \mathrm{C}$ durante 72 horas para determinação do teor de MS (AOAC, 2000). Em seguida,

Tabela 2- Composição nutricional das fontes de forragem ${ }^{1}$.

\begin{tabular}{lccc} 
Item & $\begin{array}{c}\text { Cana-de-açúcar } \\
\text { in natura }\end{array}$ & $\begin{array}{c}\text { Silagem de } \\
\text { cana }\end{array}$ & $\begin{array}{c}\text { Silagem de } \\
\text { milho }\end{array}$ \\
\hline MS, \% & $33,38 \pm 3,06$ & $29,06 \pm 1,86$ & $32,07 \pm 1,90$ \\
$\mathrm{~PB}^{2}, \%$ da MS & $1,20 \pm 0,15$ & $1,81 \pm 0,19$ & $6,31 \pm 0,51$ \\
$\mathrm{FDN}^{3}, \%$ da MS & $59,24 \pm 3,45$ & $61,19 \pm 6,53$ & $56,78 \pm 2,12$ \\
$\mathrm{FDA}^{4}, \%$ da MS & $32,45 \pm 2,00$ & $34,17 \pm 3,93$ & $27,95 \pm 1,70$ \\
Celulose $^{5}, \%$ da MS & $20,42 \pm 2,42$ & $21,89 \pm 3,50$ & $13,06 \pm 1,90$ \\
Hemicelulose $^{6}, \%$ da MS & $26,80 \pm 1,58$ & $27,02 \pm 2,82$ & $28,83 \pm 1,18$ \\
Lignina, \% da MS & $12,03 \pm 1,30$ & $12,22 \pm 1,61$ & $14,87 \pm 2,01$ \\
Cinzas, \% da MS & $1,92 \pm 0,29$ & $3,86 \pm 1,19$ & $6,82 \pm 1,47$ \\
\hline${ }^{1}$ Médias ( = 10) e desvio padrão das análises nutricionais das fontes de forragem \\
${ }^{2}$ proteina bruta; 3fibra em detergente neutro; ${ }^{4}$ fibra em detergente ácido; ${ }^{5}$ celulose = \\
FDA - lignina; 'hemicelulose = FDN - FDA
\end{tabular}

as amostras do oferecido foram moídas em moinho tipo Wiley dotado com peneira de $1 \mathrm{~mm}$ (Wiley Mill; Arthur $\mathrm{H}$. Thomas, Philadelphia, PA), e analisadas para determinação de PB, cinzas (AOAC, 2000), e FDN (Goering e Van Soest, 1970). Os resíduos de FDN foram sequencialmente analisados quanto ao teor de FDA e lignina (Goering e Van Soest, 1970). Determinou-se a concentração de celulose pela diferença entre FDA lignina, enquanto que 0 teor de hemicelulose foi calculado pela diferença entre FDN - FDA (Tabela 1).

Amostras das sobras das dietas experimentais também foram coletadas a cada 14 dias e congeladas a $-4^{\circ} \mathrm{C}$. Ao término do experimento, as amostras foram descongeladas em temperatura ambiente, reunidas para formar uma amostra composta de cada tratamento/14 dias, e levadas a uma estufa de ventilação forçada a $65^{\circ} \mathrm{C}$ durante 72 horas para determinação do teor de MS (AOAC, 2000).

O CMS foi determinado diariamente pela diferença entre a quantidade de MS oferecida e das sobras. O padrão de alimentação foi avaliado a cada 14 dias em quatro horários pós-alimentação (quatro, dez e 24 horas). Em cada tempo, a ração remanescente de cada animal alojado em baias individuais foi brevemente removida, pesada, e em seguida 
retornada ao seu respectivo animal. $O$ padrão de alimentação foi determinado pelas seguintes equações:

CMS (0-4 horas) $=\mathrm{kg}$ de MS oferecidos no tempo zero menos $\mathrm{kg}$ de MS remanescentes às 4 horas pósalimentação.

CMS (4-10 horas) $=\mathrm{kg}$ de MS remanescentes às 4 horas menos $\mathrm{kg}$ de MS remanescentes às 10 horas pósalimentação.

CMS (10-24 horas) $=\mathrm{kg}$ de MS remanescentes às 10 horas menos $\mathrm{kg}$ de MS remanescentes às 24 horas pósalimentação.

Ao longo de todo o período experimental, os animais foram pesados seis vezes a cada 14 dias após jejum de sólidos de 12 horas. Os 24 animais foram abatidos em um frigorífico localizado no município de Iporá/GO, dotado de Sistema de Inspeção Federal (SIF), após jejum de sólidos de doze horas. Após o abate, obteve-se o peso do trato gastrointestinal cheio e vazio, do fígado e das carcaças de cada animal para determinação do rendimento de carcaça quente.

O delineamento experimental utilizado foi o inteiramente casualizado em esquema fatorial $3 \times 2$ (três fontes de forragem e dois tipos de alojamento). Analisaram-se os dados pelo software $R$ (R Core Team, 2014). Os dados foram analisados por um modelo misto, considerando-se a fonte de forragem e alojamento como efeitos fixos e animal (quando os dados individuais foram disponíveis) como aleatório. No modelo incluiu-se os efeitos de fonte de forragem, alojamento, tempo, e as interações entre fonte de forragem $x$ tempo, alojamento $\times$ tempo, fonte de forragem $\times$ alojamento $e$ fonte de forragem $\times$ alojamento $\times$ tempo. Quando um efeito fixo foi significativo $(P \leq 0,05)$ ou houve tendência de significância $(0,05 \leq P \leq 0,10)$, as médias foram comparadas pelo teste de Tukey. Os valores reportados nas tabelas de resultados correspondem às médias dos quadrados mínimos e erro padrão das médias (EPM).

\section{RESULTADOS E DISCUSSÃO}

Os resultados do CMS e conversão alimentar (CA) dos animais alojados em baias individuais estão descritos na Tabela 3. Não houve influência $(P>0,05)$ da fonte de forragem sobre o CMS, expresso em $\mathrm{kg} / \mathrm{dia}$, \% do PV ou em gramas por unidade de tamanho metabólico (PV0,75). Da mesma forma, observou-se que a CA também não foi alterada $(P>0,05)$ pela fonte de forragem.

Estudos anteriores também relataram que não houve efeito da fonte de forragem ( $\mathrm{Ci}$ ou SM) sobre o CMS (Fernandes et al., 2007; Macitelli et al., 2007), o que corrobora os dados obtidos no presente estudo. Ressalta-se que os níveis nutricionais das rações experimentais tanto no presente trabalho (Tabela 1) quanto nos experimentos reportados por Fernandes et al. (2007) e Macitelli et al. (2007) foram semelhantes, indicando que a fonte de forragem não é determinante sobre o CMS e CA, desde que os níveis nutricionais das dietas sejam semelhantes. Por outro lado, Roman et al. (2011) relataram que animais em confinamento alimentados com SM aumentaram o CMS comparado à SC, porém, neste caso, os níveis de FDN e carboidratos não fibrosos (CNF) na dieta à base de $S M$ foram respectivamente de 36,7 e $42,6 \%$ do total da MS da ração, enquanto que os teores de FDN e CNF na dieta à base de SC foram de 42,1 e $37,4 \%$ do total da MS da ração, respectivamente. Portanto, o aumento do CMS nos animais alimentados com a dieta à base de SM no trabalho de Roman et al. (2011) pode ter sido causado pela variação nos níveis de FDN e CNF, e não pela fonte de forragem. 
Tabela 3- Efeito da fonte de forragem sobre o consumo de matéria seca (CMS) e conversão alimentar (CA) nos animais alojados em baias individuais.

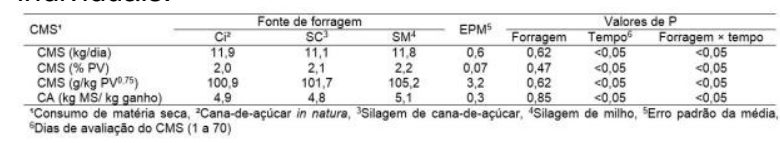

Muito se tem estudado a respeito dos fatores capazes de controlar 0 CMS, e consequentemente afetar o desempenho dos ruminantes. Porém, há um consenso que nenhum fator isolado é capaz de realizar este controle, mas sim que vários fatores atuam de forma associativa (Forbes, 1996). Receptores táteis na parede ruminal (Allen, 1996), variações nas concentrações e fluxos de nutrientes e de energia (Illius e Jessop, 1996) e o rendimento ótimo de energia líquida por unidade de oxigênio consumido (Ketelaars e Tolkamp, 1996) podem trabalhar em conjunto determinando o CMS. Isto significa que, mais do que a palatabilidade e digestibilidade de uma forragem, conhecer a forma ideal como esta é oferecida em termos de tamanho médio de partículas, proporção entre os ingredientes e balanceamento nutricional pode influenciar significativamente no CMS e consequentemente no desempenho de bovinos de corte em confinamento.

No presente estudo, as dietas experimentais foram balanceadas para serem isonitrogenadas $e$ isofibrosas. Embora a baixa digestibilidade da fibra potencialmente degradável da cana-deaçúcar pudesse levar à limitação da ingestão de MS (Pinto et al., 2009), este fator não foi capaz de causar efeito sobre o CMS nas dietas com Ci ou SC.

O padrão de alimentação não foi alterado $(P>0,05)$ pela fonte de forragem nos animais alojados em baias individuais (Tabela 4). Entretanto, verificou-se um efeito de fonte de forragem $\times$ dias, no qual os animais alimentados com $\mathrm{Ci}$ reduziram $(\mathrm{P}<0,05)$ a quantidade de MS ingerida aos 42 dias após o início do experimento (Figura 1). Observou-se também uma resposta de fonte de forragem $\times$ tempo (horas pós-alimentação), sendo que neste caso os animais alimentados com SM aumentaram $(P<0,05)$ a quantidade de MS consumida nas primeiras quatro horas pós-alimentação em relação à $\mathrm{Ci}$ e SC, aos passo que os animais alimentados com Ci aumentaram $(\mathrm{P}<0,05)$ o CMS entre dez a 24 horas pós-alimentação, comparados à SC e SM (Figura 2).

Independentemente da fonte de forragem, houve aumento $(P<0,05)$ no CMS nas primeiras quatro horas pósalimentação (5,4 kg de MS), comparado com os intervalos entre quatro a dez horas $(4,3 \mathrm{~kg}$ de MS) e entre dez a 24 horas $(2,0 \mathrm{~kg}$ de MS) (Tabela 4). Estudos prévios com vacas leiteiras também reportaram que o maior consumo de MS ocorreu nas primeiras quatro horas após o fornecimento da ração fresca no comedouro (Bhandari et al., 2008; Carvalho et al., 2012).

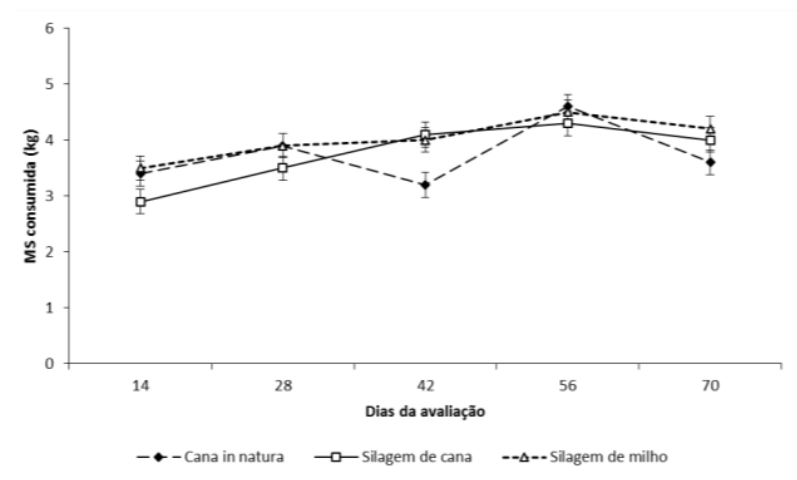

Figura 1- Efeito da fonte de forragem (Ci, SC ou SM) e dias de avaliação $(14,28,42,56$ e 70) sobre o padrão de alimentação (kg de MS consumidos). 


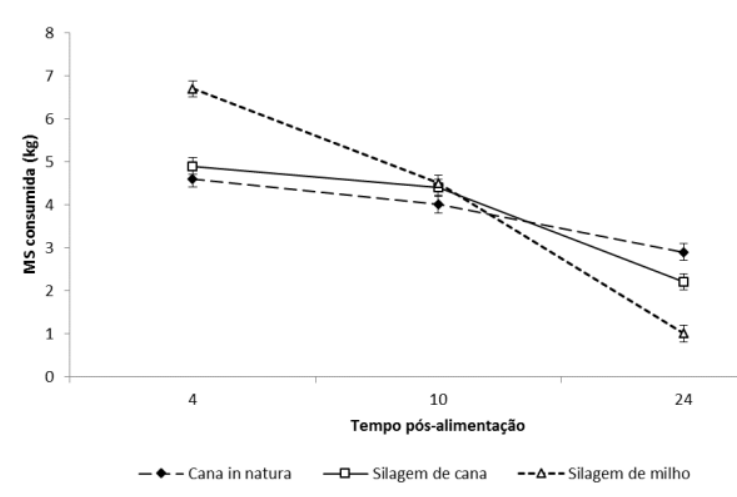

Figura 2- Efeito da fonte de forragem ( $\mathrm{Ci}, \mathrm{SC}$ ou $\mathrm{SM}$ ) e tempo pós-alimentação (0-4, 4-10 e 10-24 horas) sobre o padrão de alimentação (kg de MS consumidos).

Independentemente da fonte de forragem, houve aumento $(P<0,05)$ no CMS nas primeiras quatro horas pósalimentação (5,4 kg de MS), comparado com os intervalos entre quatro a dez horas $(4,3 \mathrm{~kg}$ de MS) e entre dez a 24 horas (2,0 kg de MS) (Tabela 4).

Tabela 4- Efeito da fonte de forragem sobre o padrão de alimentação nos animais alojados em baias individuais.

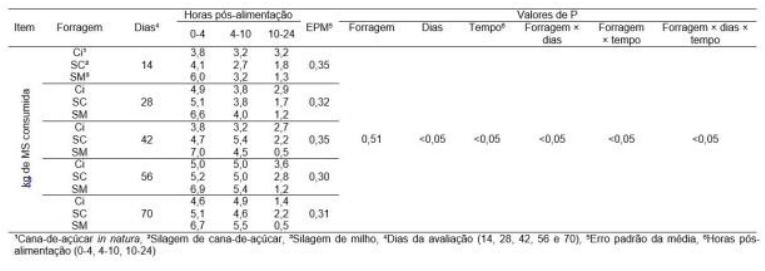

Não houve resposta $(P>0,05)$ da fonte de forragem sobre o PV em todo o período experimental (Tabela 5), reforçando a hipótese de que a fonte de forragem não exerce influência sobre o desempenho animal, desde que os níveis nutricionais das dietas sejam semelhantes. Em outros estudos, o ganho de peso diário e o PV pré-abate também não foram alterados pela fonte de forragem (Fernandes et al., 2007), mesmo quando os níveis de FDN e CNF na dieta à base de SM foram respectivamente menores e maiores em relação à dieta com SC (Roman et al., 2011), o que teoricamente poderia resultar no maior ganho de peso nos animais alimentados com SM. Por outro lado, Macitelli et al. (2007) relataram aumento no ganho de peso médio diário e PV pré-abate em animais mestiços Holandês-Zebu alimentados com SM em relação à $\mathrm{Ci}$, mas não explicaram em seu trabalho as causas deste aumento, seja em relação à composição das dietas, digestibilidade e taxa de passagem das forragens e das dietas, ou ainda pelo metabolismo de bovinos de corte alimentados com diferentes fontes de forragem. Semelhantemente, Vaz e Restle (2005) relataram aumento no PV pré-abate em novilhos da raça Hereford alimentados com dieta à base de SM em relação à dieta com $\mathrm{Ci}$. Neste trabalho, a fórmula do concentrado utilizada nas duas dietas foi a mesma, com adição de ureia na dieta com $\mathrm{Ci}$ para equilibrar o teor de PB das duas rações, entretanto não houve correção do teor de CNF e nível de energia das duas dietas, o que pode ter causado o aumento do PV pré-abate nos animais alimentados com a dieta à base de SM (Vaz e Restle, 2005).

O CMS exerce maior influência na resposta produtiva do que a digestibilidade dos componentes da dieta (Cabral et al., 2006). Assim, diferentes níveis de inclusão de forragens na ração podem resultar em variações no desempenho animal (Queiroz et al., 2008). Entretanto, desde que os parâmetros nutritivos (PB, energia e FDN) sejam ajustados para serem semelhantes ou muito próximos, como no presente estudo, espera-se que não haja diferenças no CMS e no ganho de peso, independente da fonte de forragem.

Houve tendência $(P=0,09)$ de aumento do PV nos animais alojados em baias individuais em relação ao alojamento em baias coletivas (Tabela 5). No presente estudo, a área de cada baia coletiva era de $50 \mathrm{~m}^{2} \quad(12,5$ $\mathrm{m}^{2}$ /animal), e 0 comprimento dos comedouros em cada baia era de 3,8 metros lineares $(0,95 \mathrm{~m} /$ animal $)$, o que atende e até excede as recomendações 
de construções e bem-estar para bovinos de corte em sistema de confinamento (Souza et al., 2003). No entanto, a competição pelo alimento nas baias coletivas, resultante da hierarquia social implícita no comportamento dos bovinos, provavelmente foi uma das causas da tendência $(P=0,09)$ de maior PV nos animais alojados em baias individuais. Resultados complementares a este estudo sobre as atividades de alimentação, ruminação e ócio (comportamento ingestivo) indicaram que os animais alojados em grupo despenderam mais $(\mathrm{P}<0,05)$ tempo em ócio (38,9 minutos/hora) e menos $(P<0,05)$ tempo se alimentando $(15,7$ minutos/hora), ao passo que os animais alojados individualmente tiveram 0 comportamento oposto, ou seja, menor $(\mathrm{P}<0,05)$ tempo despendido em ócio $(32,1$ minutos/hora) e maior $(P<0,05)$ tempo gasto com alimentação $(19,7$ minutos/hora).

Tabela 5- Efeito da fonte de forragem e tipo de alojamento sobre o peso vivo (PV).

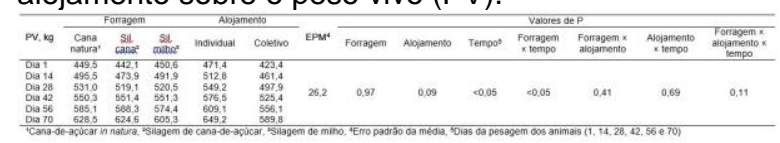

A segunda provável causa da tendência $(P=0,09)$ de aumento do $P V$ nos animais alojados em baias individuais pode ter sido o aumento da temperatura ambiente nas baias coletivas, as quais eram desprovidas de sombra. Ainda que 0 alojamento individualizado seja economicamente impraticável em sistemas de confinamento, os dados obtidos no presente estudo evidenciam que a adoção de estratégias adicionais de bem-estar animal, tais como a instalação de sombreamento artificial ou mesmo o plantio de árvores entre as baias pode promover diferenças no desempenho produtivo em bovinos confinados. O sombreamento artificial $\left(0 ; 2 ; 3,3\right.$ e $4,7 \quad \mathrm{~m}^{2} /$ animal $)$ com sombrites instalados no interior de baias coletivas no sentido norte-sul aumentou o bem-estar animal e o desempenho de 126 animais da raça Angus alimentados com a mesma dieta (Sullivan et al., 2011). Assim, pesquisas adicionais com maior número de animais alojados em baias individuais ou coletivas são necessárias para confirmar os achados obtidos no presente estudo em relação ao desenvolvimento corporal.

Os resultados de características da carcaça estão expressos na Tabela 6 . Não houve efeito $(P>0,05)$ de forragem sobre as características avaliadas, confirmando a hipótese de que a fonte de forragem não exerce influência sobre o desempenho animal desde que os níveis nutricionais da dieta sejam semelhantes. Resultados semelhantes os obtidos nesta pesquisa sobre as características da carcaça foram reportados por Fernandes et al. (2008) ao alimentarem animais da raça Canchim com dietas à base de $\mathrm{Ci}$ ou SM.

Houve resposta $(\mathrm{P}<0,05)$ de alojamento sobre 0 peso do trato gastrintestinal vazio e tendência de aumento $(0,05 \leq \mathrm{P} \leq 0,10)$ do $\mathrm{PV}$ préabate, peso do trato gastrintestinal cheio e peso do fígado nos animais alojados em baias individuais em relação às baias coletivas (Tabela 6). As prováveis causas do efeito de alojamento são as mesmas já discutidas anteriormente em relação aos dados da Tabela 5 (competição pelo alimento nas baias coletivas oriunda da hierarquia social inerente ao comportamento dos bovinos e ambiência mais favorável devido ao sombreamento nas baias individuais).

Tabela 6- Efeito da fonte de forragem e tipo de alojamento sobre as características da carcaça.

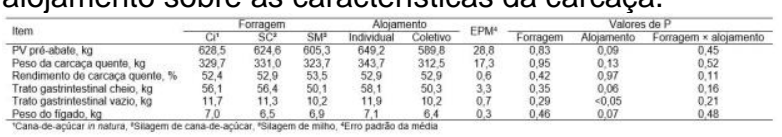

\section{CONCLUSÃO}

A Ci, SC e SM podem ser recomendadas na alimentação de 
bovinos de corte em confinamento por não terem apresentado diferenças no CMS e ganho de peso corporal. Outros fatores podem ser determinantes na escolha da fonte de forragem, tais como o custo de produção por unidade de MS ou a aptidão do produtor rural.

Pesquisas adicionais com maior número de animais alojados em baias individuais ou coletivas são necessárias para confirmar os resultados reportados nesta pesquisa em relação ao ganho de peso corporal.

\section{AGRADECIMENTOS}

Os autores deste trabalho agradecem ao médico pecuarista Dr. Esmar Gonçalves da Cunha pelo empréstimo dos 24 animais utilizados neste experimento, assim como à PROCRIA Saúde e Nutrição Animal pela mistura dos ingredientes da ração concentrada.

\section{REFERÊNCIAS}

ALLEN, M.S. Physical constraints on voluntary intake of forages by ruminants. Journal of Animal Science, v.74, n.12, p.3063-3075, 1996.

ASSOCIATION OF OFFICIAL ANALYTICAL CHEMISTS - AOAC. Official methods of analysis. $17^{\text {th }}$ edition. AOAC International, Gaithersburg, MD, 2000. 1298p.

AZEVÊDO, J.A.G.; PEREIRA, J.C.; CARNEIRO, P.C.S.; et al. Avaliação da divergência nutricional de variedades de cana-de-açúcar (Saccharum spp.). Revista Brasileira de Zootecnia, v.32, n.6, p.1431-1442, 2003.

BHANDARI, S.K.; LI, S.; OMINSKI, K.H.; et al. Effects of the chop lengths of alfalfa silage and oat silage on feed intake, milk production, feeding behavior, and rumen fermentation of dairy cows. Journal of Dairy Science, v.91, n.5, p.1942-1958, 2008.
BRONDANI, I.L.; SAMPAIO, A.A.M.; RESTLE, J.; et al. Aspectos quantitativos de carcaças de bovinos de diferentes raças, alimentados com diferentes níveis de energia. Revista Brasileira de Zootecnia, v.33, n.4, p.978-988, 2004.

CABRAL, L.S.; VALADARES FILHO, S.C.; DETMANN, E.; et al. Consumo e digestibilidade dos nutrientes em bovinos alimentados com dietas à base de volumosos tropicais. Revista Brasileira de Zootecnia, v.35, n.6, p.2406-2412, 2006.

CAMPOS, P.R.S.S.; VALADARES FILHO, S.C.; DETMANN, E.; et al. Consumo, digestibilidade e estimativa do valor energético de alguns volumosos por meio da composição química. Revista Ceres, v.57, n.1, p.7986, 2010.

CARVALHO, E.R.; SCHMELZROBERTS, N.S.; WHITE, H.M.; et al. Feeding behaviors of transition dairy cows fed glycerol as a replacement for corn. Journal of Dairy Science, v.95, n.12, p.p.7214-7224, 2012.

COSTA, M.G.; CAMPOS, J.M.S.; VALADARES FILHO, S.C.; et al. Desempenho produtivo de vacas leiteiras alimentadas com diferentes proporções de cana-de-açúcar e concentrado ou silagem de milho na dieta. Revista Brasileira de Zootecnia, v.34, n.6, p.2437-2445, 2005 (suplemento).

FERNANDES, A.R.M.; SAMPAIO, A.A.M.; HENRIQUE, W.; et al. Avaliação econômica e desempenho de machos e fêmeas Canchim em confinamento alimentados com dietas à base de silagem de milho e concentrado ou cana-de-açúcar e concentrado contendo grãos de girassol. Revista Brasileira de Zootecnia, v.36, n.4, p.855-864, 2007. 
FERNANDES, A.R.M.; SAMPAIO, A.A.M.; HENRIQUE, W.; et al. Características da carcaça e da carne de bovinos sob diferentes dietas, em confinamento. Arquivo Brasileiro de Medicina Veterinária e Zootecnia, v.60, n.1, p.139-147, 2008.

FORBES, J.M. Integration of regulatory signals controlling forage intake in ruminants. Journal of Animal Science, v.74, n.12, p.3029-3035, 1996.

FREITAS, A.W.P.; PEREIRA, J.C.; ROCHA, F.C.; et al. Avaliação da qualidade nutricional da silagem de cana-de-açúcar com aditivos microbianos e enriquecida com resíduo da colheita de soja. Revista Brasileira de Zootecnia, v.35, n.1, p.38-47, 2006.

GOERING, H.K.; VAN SOEST, P.J. Forage fiber analyses (apparatus, reagents, procedures and some applications). Agricultural Handbook no 379. Agricultural Research Service USDA, Washington, DC, 1970. 20 p.

HADLICH, J.C.; MORALES, D.C.; SILVEIRA, A.C.; et al. Efeito do colágeno na maciez da carne de bovinos de distintos grupos genéticos. Acta Scientiarum Animal Sciences, v.28, n.1, p.57-62, 2006.

HUHTANEN, P.; KHALILI, $\quad$ H.; NOUSIAINEN, J.I.; et al. Prediction of the relative intake potential of grass silage by dairy cows. Livestock Production Science, v.73, n. 2, p.111-130, 2002.

ILLIUS, A.W.; JESSOP, N.S. Metabolic constraints on voluntary intake in ruminants. Journal of animal Science, v.74, n.12, p.3052-3062, 1996.

KETELAARS, J.J.; TOLKAMP, B.J. Oxygen efficiency and the control of energy flow in animals and humans.
Journal of Animal Science, v.74, n.12, p.3036-3051, 1996.

MACITELLI, F.; BERCHIELLI, T.T.; MORAIS, J.A.S.; et al. Desempenho e rendimento de carcaça de bovinos mestiços alimentados com diferentes volumosos e fonte proteicas. Revista Brasileira de Zootecnia, v.36, n.6, p.1917-1926, 2007.

MENEZES, L.F.G.; RESTLE, J.; BRONDANI, I.L.; et al. Características da carcaça e da carne de novilhos superjovens da raça Devon terminados em diferentes sistemas de alimentação. Revista Brasileira de Zootecnia, v.39, n.3, p.667-676, 2010.

MERTENS, D.R. Predicting intake and digestibility using mathematical models of ruminal function. Journal of Animal Science, v.64, n.5, p.1548-1558, 1987.

NATIONAL RESEARCH COUNCIL - NRC. Nutrient requirements of beef cattle. $7^{\text {th }}$ revised edition. Washington, DC: National Academy Press, 2000. 242 p.

PACHECO, P.S.; RESTLE, J.; SILVA, J.H.S.; et al. Composição física da carcaça e qualidade da carne de novilhos jovens e superjovens de diferentes grupos genéticos. Revista Brasileira de Zootecnia, v.34, n.5, p.1691-1703, 2005.

PINTO, A.P.; NASCIMENTO, W.G.; ABRAHÃO, J.J.S.; et al. Digestibilidade, consumo, desempenho e características de carcaça de tourinhos mestiços confinados com cana-de-açúcar ou silagem de sorgo. Revista Brasileira de Zootecnia, v.38, n.11, p.2258-2263, 2009.

QUEIROZ, O.C.M.; NUSSIO, L.G.; SCHMIDT, P.; et al. Silagem de canade-açúcar comparada a fontes tradicionais de volumosos 
suplementares no desempenho de vacas de alta produção. Revista Brasileira de Zootecnia, v.37, n.2, p.358-365, 2008.

$\mathrm{R}$ Core Team. A language and environment for statistical computing. Viena: $R$ Foundation for Statistical Computing. 2014. Disponível em: http://www.R-project.org/.

ROMAN, J., JOBIM, C.C.; RESENDE, F.D.; et al. Performance of finishing beef cattle fed different diets containing whole-crop maize silage or sugarcane silage. Revista Brasileira de Zootecnia, v.40, n.3, p.682-689, 2011.

SOUZA, C.F.; TINOCO, I.F.F.; SARTOR, V. Informações básicas para projetos de construções rurais. Universidade Federal de Viçosa, MG, 2003. 20 p.

SULLIVAN, M.L.; CAWDELL-SMITH, A.J.; MADER, T.L.; et al. Effect of shade area on performance and welfare of short-fed feedlot cattle. Journal of Animal Science, v.89, n.9, p.29112925, 2011.

VAZ, F.N.; RESTLE, J. Características de carcaça e da carne de novilhos Hereford terminados em confinamento com diferentes fontes de volumoso. Revista Brasileira de Zootecnia, v.34, n.1, p.230-238, 2005.

VELHO, J.P.; MÜHLBACH, P.R.F.; NÖRNBERG, J.L.; et al. Composição bromatológica de silagens de milho produzidas com diferentes densidades de compactação. Revista Brasileira de Zootecnia, v.36, n.5, 1532-1538, 2007 (suplemento).

ZOPOLLATTO, M.; DANIEL, J.L.P.; NUSSIO, L.G. Aditivos microbiológicos em silagens no Brasil: revisão dos aspectos da ensilagem e do desempenho de animais. Revista Brasileira de Zootecnia, v.38, p.170189, 2009 (suplemento especial). 